\title{
An Agouti-Signaling-Protein Mutation is Strongly Associated with Melanism in European Roe Deer (Capreolus capreolus)
}

\author{
Monika Reissmann ${ }^{1}{ }^{\oplus}$, Walburga Lutz ${ }^{2}$, Dietmar Lieckfeldt ${ }^{3}$, Edson Sandoval-Castellanos ${ }^{4}(\mathbb{D}$ \\ and Arne Ludwig $1,3, *$ (i) \\ 1 Albrecht Daniel Thaer-Institute, Faculty of Life Sciences, Humboldt-University Berlin, \\ 10099 Berlin, Germany; monika.reissmann@agrar.hu-berlin.de \\ 2 Wildlife Research Institute, 53229 Bonn, Germany; lutz@pscherrer.de \\ 3 Leibniz-Institute for Zoo \& Wildlife Research, Department of Evolutionary Genetics, 10315 Berlin, Germany; \\ lieckfeldt@izw-berlin.de \\ 4 Institute of Animal Breeding and Husbandry, Kiel University, 24098 Kiel, Germany; \\ edsonsandovalc@outlook.com \\ * Correspondence: ludwig@izw-berlin.de; Tel.: +49-30-5168-312
}

Received: 21 April 2020; Accepted: 8 June 2020; Published: 11 June 2020

check for updates

\begin{abstract}
Although the European roe deer (Capreolus capreolus) population of North-West Germany has a remarkable number of melanistic specimens between $10 \%$ and $25 \%$, the underlying genetic mutation-causing melanism is still unknown. We used a gene targeting approach focusing on $M C 1 R$ and ASIP as important genes of coat coloration. Overall, $1384 \mathrm{bp}$ of MC1R and $2039 \mathrm{bp}$ of ASIP were sequenced in 24 specimens and several SNPs were detected. But only the ASIP-SNP c.33G $>$ T completely segregated both phenotypes leading to the amino acid substitution p.Leu11Phe. The SNP was further evaluated in additional 471 samples. Generally, all black specimens $(n=33)$ were homozygous TT, whereas chestnut individuals were either homozygote GG $(n=436)$ or heterozygote GT $(n=26)$. Considering the fact that all melanistic animals shared two mutated alleles of the strongly associated SNP, we concluded that melanism is inherited in a recessive mode in European roe deer.
\end{abstract}

Keywords: coat color; melanistic; cervid; ASIP; MC1R

\section{Introduction}

Melanism is a widespread phenomenon in animals. Dark phenotypes are identified in many groups of mammals including Felidae, Canidae, Cervidae and Bovidae but they are also present in insects, reptiles, birds, and other animals. Well-known melanistic animals are the black leopard (Panthera pardus) and the black jaguar (Panthera onca). In contrast to the black jaguar, where the black allele is dominant, the black mutation in leopards has a recessive mode of inheritance [1]. When compared to felids, melanistic specimens occur less frequently in cervids. In North American whitetail deer (Odocoileus virginianus) melanistic individuals are rarer than albinos ([2] and black-colored European red deer (Cervus elaphus) are also very rare. Particularly, the semi-domestic fallow deer (Dama dama) has a greater frequency of melanistic specimens which seems to be a product of artificial selection as often seen in domestic species [3]. The European roe deer (Capreolus capreolus) is the only cervid species which harbors a noteworthy natural population of melanistic specimens [4]. Although black European roe deer have been known in North-West Germany for at least several centuries and received great interest from royal houses in ancient times [5], they are less studied and even the knowledge about the genetic background of their melanism is still unknown. 
In mammals, basic coat coloration of hair and skin is defined by the ratio and distribution of the pigments eumelanin and pheomelanin [3]. Melanism is a mutation that increases the production of eumelanin in skin and hair. The darkish color of the eumelanin has a phenotypic expression from dark brown to black fur and skin [3]. In European roe deer, melanistic animals are characterized by a black coat and skin whereas the common phenotype ranges from reddish to chestnut (Figure 1).

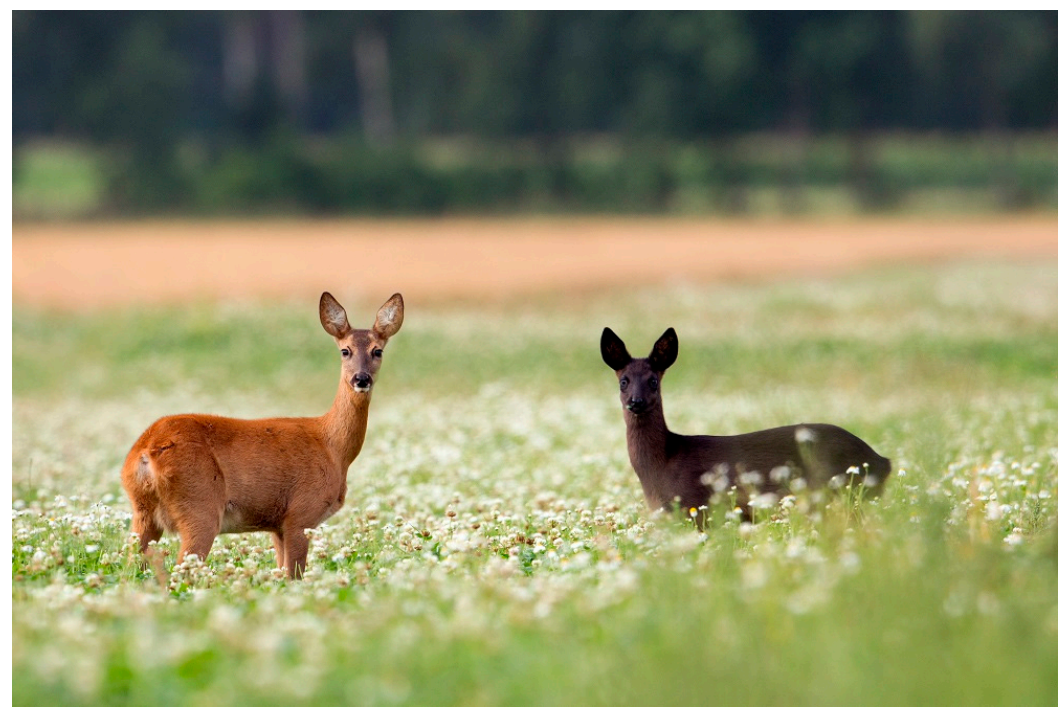

Figure 1. Chestnut and melanistic European roe deer (photo presented by Jan Piecha).

Mutations in several genes are considered as causative mechanisms for melanism. In our study, we focused on the genes of the MC1R (melanocortin 1 receptor) and the ASIP (agouti-signaling protein) as target genes for melanism in European roe deer because of their prominent roles in pigment production $[3,6-8]$.

\section{Materials and Methods}

\subsection{Sampling and DNA Extraction}

Tissue samples from 4 chestnut (Tierpark Berlin, Germany) and 20 black-colored individuals (North-West Germany and Saxony-Anhalt) were utilized for the identification of candidate mutations associated with melanism in European roe deer. Genomic DNA was extracted by incubating in $180 \mu \mathrm{L}$ T1 buffer and $20 \mu \mathrm{L}$ proteinase K (Macherey-Nagel, Berlin, Germany) followed by a salting out procedure [9].

\subsection{Sequencing of Target Genes}

The draft genome of European roe deer (>lcl|Deer_k43_scaffold143768:28399-31352 10.1, [10]) and the $M C 1 R$ sequence of roe deer (Y13960) were utilized for the primer design of the melanocortin 1 receptor (MC1R) gene. For the agouti-signaling protein $(A S I P)$ gene, no reference sequence was available from the cervid species. The draft version of the European roe deer genome (>lcl|Deer_k43_scaffold320422:2380-9700 $13.5,[10])$ was utilized for primer design in addition with the equine ASIP sequence (AF288358).

The DNA of 4 individuals representing the chestnut phenotype and 20 melanistic roe deer were amplified in a volume of $35 \mathrm{~mL}$ containing $50 \mathrm{ng}$ DNA, $0.2 \mu \mathrm{M}$ of each primer, $0.2 \mathrm{mM} \mathrm{dNTP}, 2.5 \mathrm{mM}$ $\mathrm{MgCl}_{2}$, and $1 \mathrm{U}$ GoTaqflexi polymerase (Promega, Madison, WI, USA). This was followed by PCR which included a denaturation step at $95{ }^{\circ} \mathrm{C}(5 \mathrm{~min})$ followed by 35 cycles of denaturation at $94{ }^{\circ} \mathrm{C}$ (60 s), annealing at primer specific temperature (30 s), and elongation at $72{ }^{\circ} \mathrm{C}(45 \mathrm{~s})$. The final elongation step was carried out at $72{ }^{\circ} \mathrm{C}$ for $5 \mathrm{~min}$. After running on a $2 \%$ agarose gel for $30 \mathrm{~min}$, the PCR fragments were cut out of the agarose gel and cleaned with a GeneJet Gel Extraction Kit 
(Fermentas, Thermo Fisher Scientific, Waltham, MA, USA). The sequencing was carried out as a Sanger reaction with a BigDye Terminator v1.1 Ready Reaction Cycle Sequencing Kit in an ABI PRISM 310 Genetic Analyzer (Life Technologies, Thermo Fisher Scientific, Waltham, MA, USA) applying the manufacturer's protocol.

\subsection{Calculation of Amino Acid Substitution Effect}

The possible effects of amino acid substitution were calculated by comparing 44 ASIP sequences from GenBank with SIFT (https://sift.bii.a-star.edu.sg/www/SIFT_seq_submit2.html) using standard settings.

\subsection{Test of Target Mutations}

The identification of causative mutations for specific phenotypes is often a challenge in wild animals. In domestic animals and model species, pedigree data are available and crossbreeding is a possible tool for identification of underlying genetics, but other strategies have to be utilized for wild animals. We utilized a test approach for evaluation of the black mutation in European roe deer. Samples of 317 specimens from North-West Germany, 127 from United Kingdom and 27 from Saxony-Anhalt were included in a blind test scenario. A protocol was drawn up for each European roe deer shot, in which the coat color was recorded in addition to the specimen's location. This phenotypic information was available after genotyping. Our approach was methodically adopted to the specifics of investigations of wild animals. In the end, the association between genotypes and phenotypes was statistically validated for the candidate mutations. Genotyping of the target ASIP-SNP (c.33G >T) was done with KBiosciences Allele Specific PCR (KASP) technology using standard procedure and a $57^{\circ} \mathrm{C}$ touch-down PCR approach (LGC Genomics, Berlin, Germany). Primer sequences, fragment lengths, and annealing temperatures are listed in Table 1 below.

Table 1. Primers and annealing temperatures.

\begin{tabular}{|c|c|c|c|}
\hline Primer & Sequence $5^{\prime}-3^{\prime}$ & Length & Temp. \\
\hline MC1R-1 up & CCC ACG GGC CAG GAG GAA & 708 bp & $62^{\circ} \mathrm{C}$ \\
\hline MC1R-1 low & GCA GGG CGT AGA AGA TGG AGA TGT & & \\
\hline MC1R-2 up & GCC ATC GCC AAG AAC CGC AAC C & 944 bp & $63^{\circ} \mathrm{C}$ \\
\hline MC1R-2 low & ACC ATC TCC CCA GCC TCC TCA TTC & & \\
\hline ASIP-A up & GGC ATT ACT GGG GAC CTA TCA AC & $941 \mathrm{bp}$ & $56^{\circ} \mathrm{C}$ \\
\hline ASIP-A low & CAA CCC TGG CAT GAA AGA ACT A & & \\
\hline ASIP-B up & CCC CAA GCC GCT ATC AGG A & $1068 \mathrm{bp}$ & $56^{\circ} \mathrm{C}$ \\
\hline ASIP-B low & TGC AGA CCT AGA GCC AGA GAC & & \\
\hline ASIP-C up & GGG ATA CCG GAA ACA CAA GAC CAT & $469 \mathrm{bp}$ & $56^{\circ} \mathrm{C}$ \\
\hline ASIP-C low & GGC ATG CAA CCC TGG ACA ATC & & \\
\hline ASIP-33-A1 & GAA GCA CAG GCA GGC CAG C & $44 \mathrm{bp}$ & $57^{\circ} \mathrm{C}$ \\
\hline ASIP-33-A2 & GGA AGC ACA GGC AGG CCA GA & & \\
\hline ASIP-33-C & CAG CCG CCT CCT CCT GGC TA & & \\
\hline
\end{tabular}

\subsection{Statistical Analysis}

After identifying a candidate gene mutation for melanism, we tested the genotype counts for Hardy-Weinberg equilibrium. Then, we tested if genotype-phenotype combinations significantly departed from randomness by means of contingency-table tests. Finally, to test specifically if the candidate genotype (TT) was the cause of melanism, we applied a custom test that consisted of calculating the one-tail probability of observing less TT genotypes in non-melanistic (chestnut) individuals than in the observed empirical sample. The rationale is that if TT is a causative variant of melanism there will be an excess of individuals with both TT genotypes and melanism than would be expected by chance. This is the same as measuring the deficit of non-melanistic individuals with TT genotype, which is easier to compute. The obtained probability can be interpreted as a $p$-value of the one-tail test of TT being overrepresented in individuals with melanism.

For this reason, we employed a multinomial distribution with categories of phenotype-genotype combinations, and unknown population frequencies were approached by sampling frequencies. We replicated the analysis to discard the effect of different subjective choices. For instance: Should the 


\subsection{Result of the Genetic Test}

The most promising SNP in exon 1 of ASIP was targeted in a blind test. A total of 471 European roe deer from different regions in Germany and United Kingdom were genotyped with an Allele Specific PCR (KASP) for the SNP c.33G>T (Table 3). In the post-genotype comparison with the coat color phenotypes, it was found that all melanistic animals were homozygous TT at position c.33, while the chestnut individuals were either homozygous GG or heterozygous GT but never homozygous TT.

Table 3. Results of blind test of SNP c.33G $>$ T in 471 European roe deer (details in Table S1).

\begin{tabular}{|c|c|c|c|c|}
\hline Origin & GG & GT & TT & Phenotype \\
\hline $\begin{array}{l}\text { North-West } \\
\text { Germany }\end{array}$ & 281 & & & Chestnut \\
\hline & & 25 & 11 & $\begin{array}{l}\text { Chestnut } \\
\text { Black }\end{array}$ \\
\hline United Kingdom & 126 & 1 & & $\begin{array}{l}\text { Chestnut } \\
\text { Chestnut }\end{array}$ \\
\hline $\begin{array}{c}\text { Saxony-Anhalt } \\
\text { Germany }\end{array}$ & 25 & & & Chestnut \\
\hline & & & 2 & Black \\
\hline
\end{tabular}

The observed associations were nonrandom in the pooled sample as well as for North-West Germany, and Saxony-Anhalt, Germany, while non-computable for the United Kingdom sample because it lacked melanistic individuals in general (Table 4). The total absence of TT genotypes in chestnut specimens produced exceedingly low probabilities in the contingency tests and astronomically low probabilities in the multinomial test. As expected, local samples, except from the United Kingdom, had higher values than the pooled ones, especially Saxony-Anhalt, Germany, due to their lower sample size. In general, the complete association of TT genotypes and melanistic individuals with the large sample sizes (almost 500 in the pooled sample) provides strikingly high statistical support to the hypothesis of the TT genotype causing melanism.

Table 4. Tests of randomness of genotype and phenotype frequencies. Multinomial and contingency table tests were carried out for different types of categories for genotypes, for each geographical sample, and with two or three genotype categories. As we tested associations with two phenotypes hypothesized to be caused by two genotype categories, a two genotype categories test was statistically justified. NA means that the test was not able to be computed, generally because of mathematical obstacles (e.g., a division by zero).

\begin{tabular}{|c|c|c|c|c|c|}
\hline & $\begin{array}{l}\text { Type of Genotype } \\
\text { Categories }\end{array}$ & $\begin{array}{c}\text { Nr. of Genotype } \\
\text { Categories }\end{array}$ & Sample & $x^{2}$ & $p$-Value \\
\hline \multirow{20}{*}{$\begin{array}{l}\text { Contingency } \\
\text { table }\end{array}$} & \multirow{8}{*}{$\begin{array}{l}\text { Independent } \\
\text { genotypes }\end{array}$} & \multirow{4}{*}{ 2: (GG/GT), (TT) } & North-West Germany & 341.00 & $<1.0 \times 10^{-10}$ \\
\hline & & & United Kingdom & $\mathrm{NA}^{*}$ & NA* \\
\hline & & & Saxony-Anhalt Germany & 27.000 & $2.03 \times 10^{-7}$ \\
\hline & & & Pooled & 495.00 & $<1.0 \times 10^{-10}$ \\
\hline & & \multirow{4}{*}{ 3: (GG), (GT), (TT) } & North-West Germany & 341.00 & $<1.0 \times 10^{-10}$ \\
\hline & & & United Kingdom & NA * & $\mathrm{NA}^{*}$ \\
\hline & & & Saxony-Anhalt Germany & 27.000 & $1.37 \times 10^{-6}$ \\
\hline & & & Pooled & 495.00 & $<1.0 \times 10^{-10}$ \\
\hline & \multirow{8}{*}{$\begin{array}{c}\text { Hardy-Weinberg } \\
\text { equilibrium }\end{array}$} & \multirow{4}{*}{ 2: (GG/GT), (TT) } & North-West Germany & 1879.1 & $<1.0 \times 10^{-10}$ \\
\hline & & & United Kingdom & $0.00196^{* *}$ & $0.9646^{* *}$ \\
\hline & & & Saxony-Anhalt Germany & 362.64 & $<1.0 \times 10^{-10}$ \\
\hline & & & Pooled & 3792.3 & $<1.0 \times 10^{-10}$ \\
\hline & & \multirow{4}{*}{ 3: (GG), (GT), (TT) } & North-West Germany & 1917.3 & $<1.0 \times 10^{-10}$ \\
\hline & & & United Kingdom & $0.00198^{* *}$ & $0.999 * *$ \\
\hline & & & Saxony-Anhalt Germany & 366.66 & $<1.0 \times 10^{-10}$ \\
\hline & & & Pooled & 3835.0 & $<1.0 \times 10^{-10}$ \\
\hline & \multirow{4}{*}{ By alleles } & \multirow{4}{*}{ Alleles: $(\mathrm{G}),(\mathrm{T})$} & North-West Germany & 466.43 & $<1.0 \times 10^{-10}$ \\
\hline & & & United Kingdom & NA * & $\mathrm{NA}^{*}$ \\
\hline & & & Saxony-Anhalt Germany & 54.000 & $<1.0 \times 10^{-10}$ \\
\hline & & & Pooled & 690.23 & $<1.0 \times 10^{-10}$ \\
\hline
\end{tabular}


Table 4. Cont.

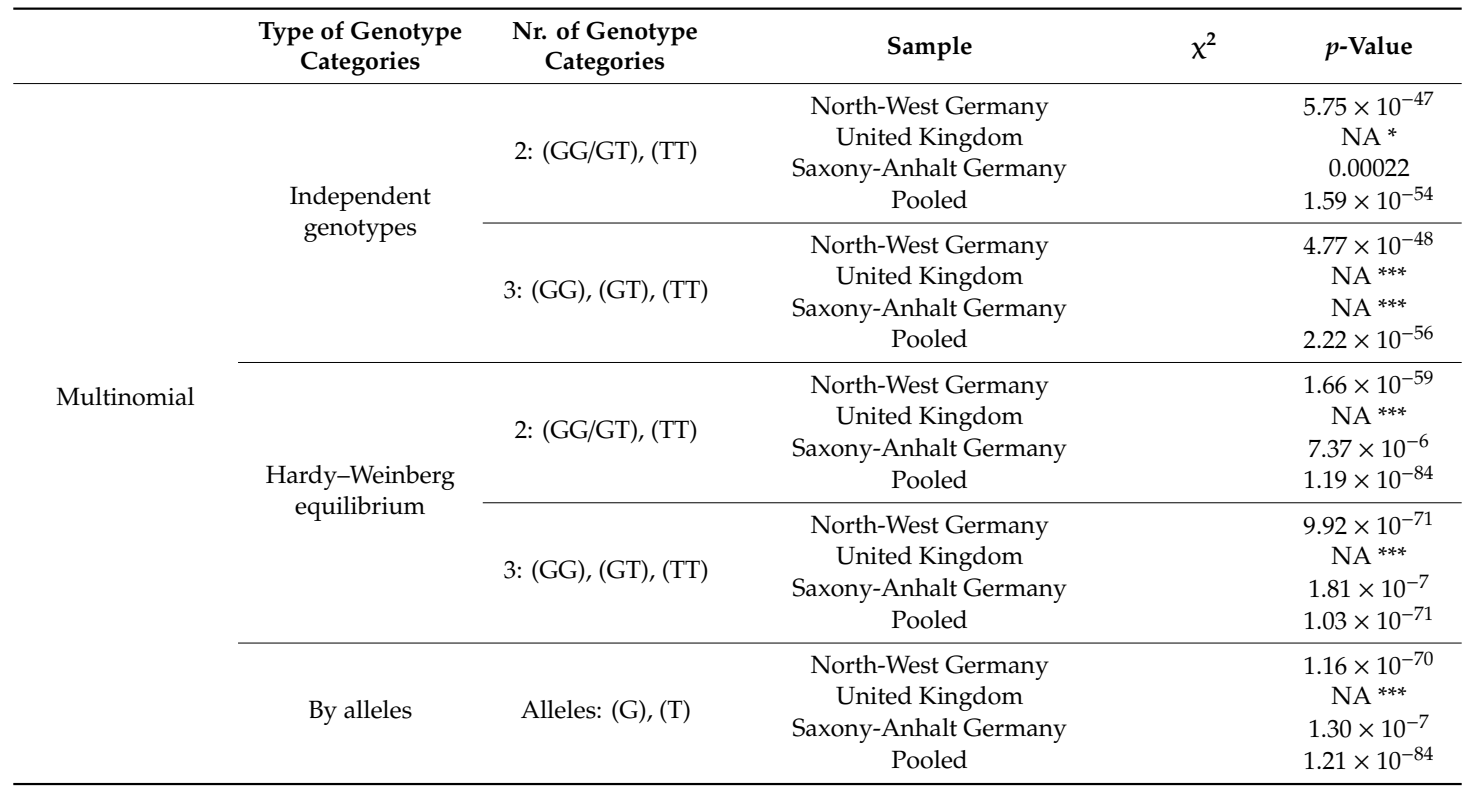

* Not computable, too many zeros. ** Dubious validity, too many missing categories. *** Not computable, undetermined value.

The genotype frequencies were also strong in Hardy-Weinberg disequilibrium in North-West Germany $\left(p\right.$-value $\left.<1.0 \times 10^{-8}\right)$, Saxony-Anhalt, Germany $\left(p\right.$-value $\left.=1.4 \times 10^{-6}\right)$, and pooled $\left(p\right.$-value $\left.<1.0 \times 10^{-8}\right)$, but not in the United Kingdom samples $(p$-value $=0.999)$.

\section{Discussion}

The MC1R has an important role in the alternative activation of the metabolic pathway of production of the pigments eumelanin (blackish) and pheomelanin (reddish). As a result, all carriers of a dominant black allele of $M C 1 R$ will have black fur. The black jaguar is a well-known example of a dominant black MC1R mutation [1]. However, the MC1R-SNP c.444C $>\mathrm{T}$ found in European roe deer is a synonymous mutation and does not segregate in both phenotypes. Therefore, we exclude the $M C 1 R$ as the reason for blackening in European roe deer.

In many species, the coat color arises, apart from possible lightening and spotting [3], through the interaction of the MC1R with the antagonistic ASIP. In contrast to the systemic active MC1R, ASIP acts at a local scale only. Due to the local expression of $A S I P$, the genetic ability to produce black eumelanin is reduced to certain areas of the body. We observed four SNPs in ASIP (Table 2), but only the SNP c.33G $>$ T segregated both phenotypes. All black-colored European roe deer were homozygous TT at this SNP. This outcome was confirmed by our blind test of 471 specimens in which the black phenotype was assigned after genotyping all homozygous TT animals $(n=13)$, while chestnut specimens shared either the homozygote GG genotype $(n=432)$ or the heterozygote GT genotype $(n=26)$ (Table 2$)$. With the addition of these specimens to the originally tested 24 specimens (TT $=20 ; 4=G G$ ), this sample set provided a respectable statistical power that resulted in extremely low probabilities of being caused by sampling error alone (Table 4). Values were still highly significant for each geographical location as long as the tests were possible. The high significance was also unaffected by considering Hardy-Weinberg equilibrium or different genotype systems, strongly suggesting that the melanistic phenotype has no plasticity or epigenetic components and is rather caused by a single substitution.

The substitution of $\mathrm{G}$ by $\mathrm{T}$ causes an amino acid exchange (p.Leu11Phe) which produces evidence for intolerance of protein function. Notably, white-tailed deer (XM_020889165), horses [11], wild cattle [12], pig [13], sheep [14], and human [15] also have the leucine variant at the amino acid position mentioned (Figure 2), indicating its basal origin. It is likely that leucine is the non-mutated, primitive character of this triplet, which seems to allow ASIP to suppress the blackish eumelanin 
by blocking the MC1R, resulting in the common phenotype of chestnut-colored European roe deer as reported for many other species. Chestnut-colored European roe deer can have an active ASIP suppressing the blackish eumelanin on nearly their entire body (Figure 1).

Chestnut-colored European roe deer have at least one non-mutated allele. In contrast, all black animals had two mutated alleles, which produced a strong association of the black color and the reported SNP. This would result in a recessive mode of inheritance of the mutated ASIP allele, which is also found in leopards, horses, and other animals [1,11,16].

Altogether and regardless of other genetic reasons for melanism, e.g., [17-23], investigation of segregation of both alleles, mutated and non-mutated, in a set of 495 samples produced a perfect association resulting in extremely high statistical support under different scenarios and providing strong arguments that the mutation c.33.G>T causes the black phenotype in European roe deer. Considering the high frequency of melanistic individuals in the North-West German lowland population, it cannot be excluded that melanism had a selective advantage (e.g., camouflage) as previously discussed for other species $[3,18,24]$. In addition, artificial selection based on human preferences (e.g., hunting restrictions) is a likely reason for its frequent occurrence. Although this study focused on two important genes for melanism in European roe deer, a genome-wide association study and expression analysis should be done to give information about the possibility of further associated genes to the black coat color in European roe deer.

Supplementary Materials: The following are available online at http://www.mdpi.com/2073-4425/11/6/647/s1, Figure S1: Alignment of $M C 1 R$ based on European roe deer sequences from the whole genome sequencing, the GenBank sequence, the chestnut and the black roe deer. Figure S2: Alignment of ASIP based on sequences of the European roe deer from the whole genome sequencing, a chestnut and a melanistic individual, and the equine mRNA sequence. Table S1: Table of origin, coat color phenotype and genotype for SNPs for 495 European roe deer.

Author Contributions: Conceptualisation, A.L., M.R., W.L.; Methodology, M.R., A.L.; D.L.; Investigation, A.L., M.R., D.L., E.S.-C.; Resources, W.L., A.L.; Statistics, E.S.-C.; Writing-Original Draft Preparation, A.L., M.R.; Writing-Review \& Editing, A.L., M.R., E.S.-C., W.L.; Visualisation, A.L., M.R., E.S.-C., W.L.; Supervision, A.L., M.R., W.L.; Project Administration, A.L., W.L.; Funding Acquisition, A.L., W.L. All authors have read and agreed to the published version of the manuscript.

Funding: We appreciate the Wildlife Research Institute, North-Rhine Westphalia, Germany as this study was supported by grants (FJW 10261-53762/06-2014000156) from it.

Acknowledgments: We are obliged to persons who generously supported in collecting samples and data. Our analyses would not have been possible if not for the great support from numerous hunters and forest rangers as well as local and federal state hunting organizations and administrations. In particular, our profound gratitude goes to hunters and owners of hunting grounds inhabited by melanistic European roe deer, and to forest and veterinarian administrations of North-Rhine Westphalia and Saxony-Anhalt and scientists of the former Young Researcher Group of Wildlife Diseases of the Friedrich-Loeffler-Institut. We also thank K. H. Baker for samples from the UK. Special thanks go to J. Piecha for providing the photo.

Conflicts of Interest: The authors declare no conflict of interest.

\section{References}

1. Eizirik, E.; Yuhki, N.; Johnson, W.E.; Menotti-Raymond, M.; Hannah, S.S.; O’Brien, S.J. Molecular genetics and evolution of melanism in the cat family. Curr. Biol. 2003, 13, 448-453. [CrossRef]

2. Rue, L.L., III. The Deer of North America; Crown Publishers Inc.: New York, NY, USA, 1978; ISBN 978-1592284658.

3. Cieslak, M.; Reissmann, M.; Hofreiter, M.; Ludwig, A. Colours of domestication. Biol. Rev. 2011, 86, 885-899. [CrossRef] [PubMed]

4. Meyer-Brenken, H. Das Schwarze Rehwild; Landbuch Verlagsgesellschaft mbH.: Hannover, Germany, 1982; ISBN 9783784200026.

5. Brandt, C. Das Schwarze Rehwild; Druck und Verlag von Friedr. Scheel: Kassel, Germany, 1889.

6. Rees, J.L. Genetics of Hair and Skin Color. Annu. Rev. Genet. 2003, 37, 67-90. [CrossRef] [PubMed]

7. Hoekstra, H. Genetics, development and evolution of adaptive pigmentation in vertebrates. Heredity 2006, 97, 222-234. [CrossRef] [PubMed]

8. Suzuki, H. Evolutionary and Phylogeographic Views on Mc1r and Asip Variation in Mammals. Genes Genet. Syst. 2013, 88, 155-164. [CrossRef] [PubMed] 
9. Miller, S.A.; Dykes, D.D.; Polesky, H.F. A simple salting out procedure for extracting DNA from human nucleated cells. Nucleic Acids Res. 1988, 16, 1215. [CrossRef] [PubMed]

10. Kropatsch, R.; Dekomien, G.; Akkad, D.A.; Gerding, W.M.; Petrasch-Parwez, E.; Young, N.D.; Altmüller, J.; Nürnberg, P.; Gasser, R.B.; Epplen, J.T. SOX9 Duplication linked to intersex in deer. PLoS ONE 2013, 8, e73734. [CrossRef] [PubMed]

11. Rieder, S.; Taourit, S.; Mariat, D.; Langlois, B.; Guérin, G. Mutations in the agouti (ASIP), the extension (MC1R), and the brown (TYRP1) loci and their association to coat color phenotypes in horses (Equus caballus). Mamm. Genome 2001, 12, 450-455. [CrossRef] [PubMed]

12. Royo, L.J.; Alvarez, I.; Fernandez, I.; Arranz, J.J.; Gomez, E.; Goyache, F. The coding sequence of the ASIP gene is identical in nine wild-type coloured cattle breeds. J. Anim. Breed. Genet. 2005, 122, 357-360. [CrossRef] [PubMed]

13. Mao, H.; Ren, J.; Ding, N.; Xiao, S.; Huang, L. Genetic variation within coat color genes of MC1R and ASIP Chinese brownish red Tibetan pigs. Anim. Sci. J. 2010, 81, 630-634. [CrossRef] [PubMed]

14. Norris, B.J.; Whan, V.A. A gene duplication affecting expression of the ovine ASIP gene is responsible for white and black sheep. Genome Res. 2008, 18, 1282-1293. [CrossRef] [PubMed]

15. Zhang, M.; Song, F.; Liang, L.; Nan, H.; Zhang, J.; Liu, H.; Wang, L.E.; Wei, Q.; Lee, J.E.; Amos, C.I.; et al. Genome-wide association studies identify several new loci associated with pigmentation traits and skin cancer risk in European Americans. Hum. Mol. Genet. 2013, 22, 2948-2959. [CrossRef] [PubMed]

16. Reissmann, M.; Ludwig, A. Pleiotropic effects of coat colour-associated mutations in humans, mice and other mammals. Semin. Cell Dev. Biol. 2013, 6-7, 576-586. [CrossRef] [PubMed]

17. Candille, S.I.; Kaelin, C.B.; Cattanach, B.M.; Yu, B.; Thompson, D.A.; Nix, M.A.; Kerns, J.A.; Schmutz, S.M.; Millhauser, G.L.; Barsh, G.S. A $\beta$-defensin mutation causes black coat color in domestic dogs. Science 2007, 318, 1418-1423. [CrossRef] [PubMed]

18. Anderson, T.M.; von Holdt, B.M.; Candille, S.I.; Musiani, M.; Greco, C.; Stahler, D.R.; Smith, D.W.; Padhukasahasram, B.; Randi, E.; Leonard, J.A.; et al. Molecular and evolutionary history of melanism in North American gray wolves. Science 2009, 323, 1339-1343. [CrossRef] [PubMed]

19. Sponenberg, D.P.; Bellone, R. Equine Color Genetics; Wiley-Blackwell: Hoboken, NJ, USA, 2017; ISBN 978-1-119-13058-1.

20. Weich, K.; Affolter, V.; York, D.; Rebhun, R.; Grahn, R.; Kallenberg, A.; Bannasch, D. Pigment Intensity in Dogs is Associated with a Copy Number Variant Upstream of KITLG. Genes 2020, 11, 75. [CrossRef] [PubMed]

21. Corbin, L.J.; Pope, J.; Sanson, J.; Antczak, D.F.; Miller, D.; Sadeghi, R.; Brooks, S.A. An Independent Locus Upstream of ASIP Controls Variation in the Shade of the Bay Coat Colour in Horses. Genes 2020, 11, 606. [CrossRef] [PubMed]

22. Yang, N.; Zhao, B.; Hu, S.; Bao, Z.; Liu, M.; Chen, Y.; Wu, X. Characterization of POU2F1 Gene and Its Potential Impact on the Expression of Genes Involved in Fur Color Formation in Rex Rabbit. Genes 2020, 11, 575. [CrossRef] [PubMed]

23. Reissmann, M.; Musa, L.; Zakizadeh, S.; Ludwig, A. Distribution of coat-color-associated alleles in the domestic horse population and Przewalski's horse. J. Appl. Genet. 2016, 57, 519-525. [CrossRef] [PubMed]

24. Sandoval-Castellanos, E.; Wutke, S.; Gonzalez-Salazar, C.; Ludwig, A. Coat colour adaptation of post-glacial horses to increasing forest vegetation. Nat. Ecol. Evol. 2017, 1, 1816-1819. [CrossRef] [PubMed]

(C) 2020 by the authors. Licensee MDPI, Basel, Switzerland. This article is an open access article distributed under the terms and conditions of the Creative Commons Attribution (CC BY) license (http://creativecommons.org/licenses/by/4.0/). 